\title{
The Preservation of the Relict Irtysh Pine Forests
}

\author{
Mazbayev OB, Belgibaev ME, Demeuov AB* \\ ${ }^{1}$ Department of Physical and Economic Geography, L.N Gumilev ENU, Kazakhstan \\ ${ }^{2}$ Department of Physical Geography, Shakarim State University, Kazakhstan \\ ${ }^{3}$ Abai Kazakh National Pedagogical University, City of Almaty, Kazakhstan
}

*Corresponding author: Demeuov AB, Abai Kazakh National Pedagogical University, City of Almaty, Kazakhstan, Email: arman_demeuov@mail.ru

\section{Review Article \\ Volume 4 Issue 3}

Received Date: March 05, 2020

Published Date: April 06, 2020

DOI: $10.23880 /$ jenr- 16000196

\section{Abstract}

The main arrays of belt hogs are located in the Altai. Their name is consonant with the names of the small rivers flowing through them - the Barnaulka, Kasmala, Burla, Kulundy. The longest is the Barnaul pine forest belt, which stretches for 550 $\mathrm{km}$ from the Ob River in the vicinity of Barnaul to the Irtysh River in the vicinity of Semey in Kazakhstan. Experts still argue about the age and origin of hogs and growing conditions. The most common version is that the belt forests were left after the last ice age, which was observed about 10,000 years ago. Then the territory between Ob and Irtysh was located between two huge glaciers. During the melting of glaciers, water flows carried masses of sand, which gradually accumulated in the bottoms of narrow and long hollows. Later, pine trees began to grow on the deposited sands. This is the secret of the unusual linear arrangement of these forests. Over the millennia, a unique landscape has developed: forests grow in the hollows, and steppes dominate the spaces between them.

Keywords: Tourecological Path; Tourecological Route; Especially Guarded Natural Territory

\section{Introduction}

The origin and conservation of the Irtysh relic pine forest was described by us in 2014 in the Journal of Balkan Ecology. Following this publication, we wanted to tell you about the ecological state of pine forests in Kazakhstan at the present time.

Kazakhstan belongs to low-forest States. The vulnerability of forests is very high, which is caused by the natural and climatic conditions of the territory. Belt of the forest are normal of natural formations from the period of ice cover. The Priirtyshya (at the river Ertis) ribbon forest is located on the right bank of the Irtysh river, on the territory of two regions of Kazakhstan-East Kazakhstan and Pavlodar regions of Kazakhstan.

Only Canada has an analogue of this unique natural product that performs climate-regulating, sanitary-hygienic, soil protection and water protection functions. The total area of the belt forest is 870.5 thousand hectares. the forest-forming breed is common pine (Pinus Silvestris). These forests are relict and have great ecological and socioeconomic significance. In the global arid zone of the planet, there are only two unique belts of relict pine forests. The first in Canada, the second in Kazakhstan and Russia (Figure 1).

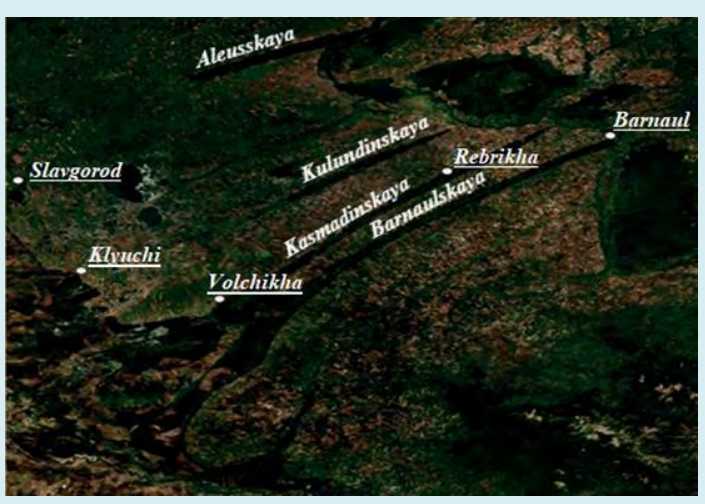

Figure 1: The scheme of the Ribbon forest (klad-altaya.ru). 
The question arises as there were tape forests in the study area. The process of occurrence of relict pine forests with the overflow of glacial waters in the Ob-Irtysh basin is considered. From the overflow of the $\mathrm{Ob}$ river, blocked by a glacier with a height of 300 to $500 \mathrm{~m}$, abundant water flowed in a south-westerly direction, creating belt forests: Kulundinsky, Kasmalinsky and Barnaul belts. In these basins, after 2-3 thousand years, the common pine (Pinus Sibirika) moved to the right bank of the Irtysh river. On the right bank of the Irtysh river, sand deposits have accumulated, stirred by an ancient stream that flows down from the left bank of the $\mathrm{Ob}$ river. Belt pine forests appeared on these sandy deposits [1].

Thus, in the Irtysh basin on the right Bank of the Irtysh river, a belt of pine forest extends. Over the past decade, the pine forest has undergone significant changes as a result of numerous fires, deforestation, and poaching [2]. Pine forests were mostly affected by forest fires between 1990 and 2010 (Figure 2).

At this time, it is important to restore of burnt forest (forest area with a stand of trees that died from a fire). For this purpose, every winter foresters collect pinecones, process them in a special way and get seeds. Then, in six nurseries, the seeds are carefully sprouted, and after two long years, necessarily in april, the seedlings are planted on pre-cleared of burnt forest. The survival rate, according to experts, is high-60 percent. Every year the number of seedlings increases [3]. The territory of Kazakhstan's belt forests will be restored in about 10 years, chief expert of the Committee of forestry and wildlife of the Ministry of Agriculture of the Republic of Kazakhstan Sergey Turumbayev said [4].

The territory of the belt hogs is being restored but already today 200 thousand hectares have been lost to date only 130 thousand hectares have been restored. According To the forestry and hunting Committee of the Ministry of agriculture, during the fire-dangerous period of 2018, 333 fires were registered on the territory of JSC «Semey ormany» (the woods of Semey) on the area of 404 hectares of forest land, material damage amounted to more than 25 million tenge. 1,225 cubic meters of wood were burned.

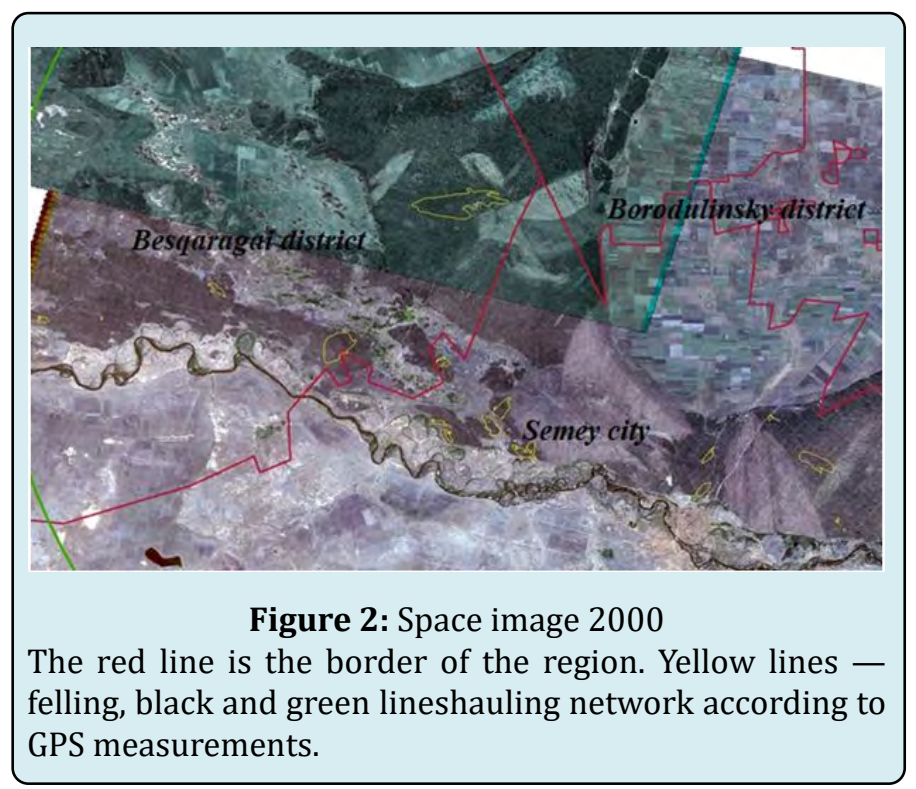

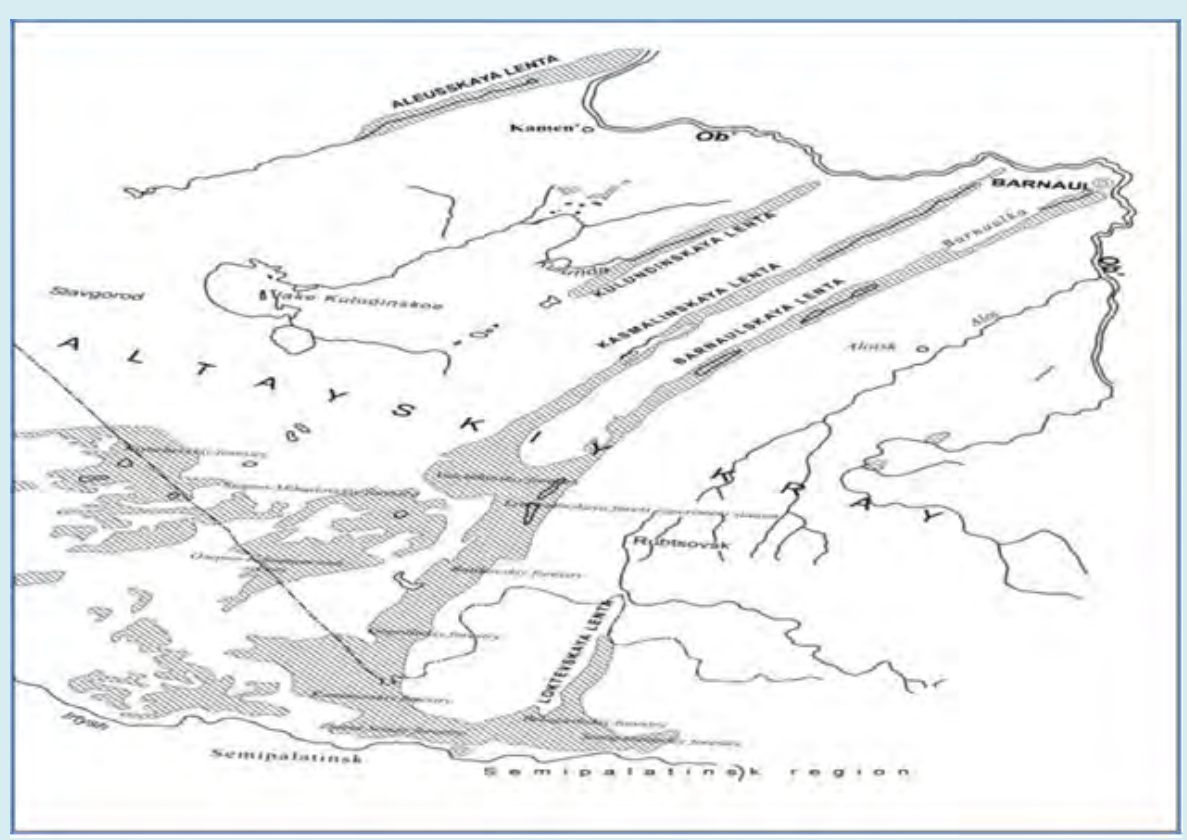

Figure 3: Location scheme of the Priobsky forest belt, including the Irtysh pine forest. 


\section{Journal of Ecology and Natural Resources}

Pine forests grow on ancient Aeolian Sands and sandy loams. Deforestation by fires and fallen solid mass leads to the movement of sand with constantly blowing winds: deflation and Aeolian processes. On the right Bank of the Irtysh river, sections of the sandy embankment have already been marked. Moving in a south-westerly direction, it can cover the Irtysh river. All this will help to strengthen and expand the desertification of the steppe zone. Naturally, intelligent human activity should not lead to such an anthropogenic environmental disaster. Desertification of the steppe zone is considered an environmental problem (Figure 3).

In order to preserve the relict pine forest, a biosphere reserve must be created under the auspices of UNESCO, similar to a similar reserve in Canada. Only in this way can we preserve the pine forests for future generations. Currently, work is underway to restore forests in burned areas.

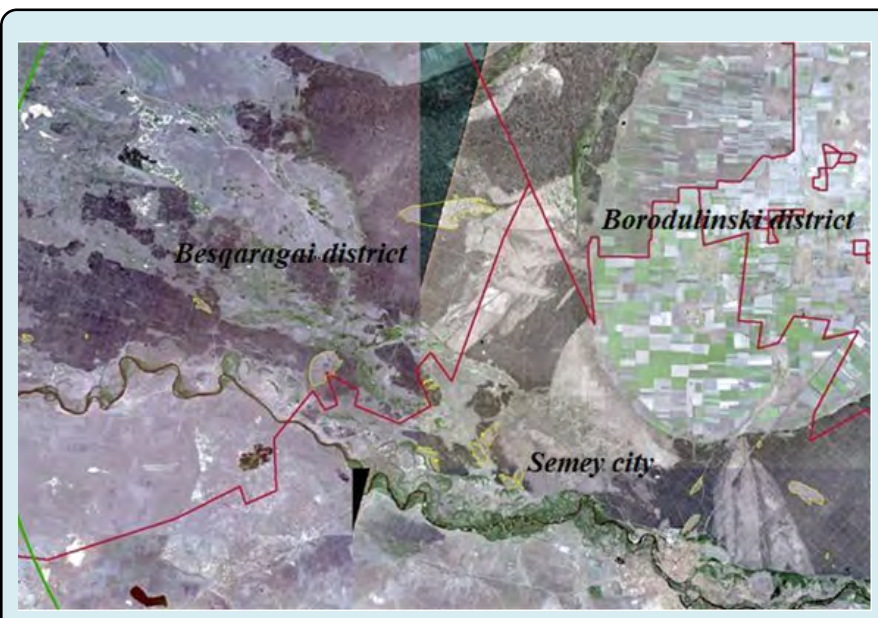

Figure 4: Space image 2019.

The red line is the border of the region. Yellow lines - the cabin, black-and-green fire-a network of hauls according to GPS measurements

The region has a huge tourist and recreational potential due to its natural and climatic, historical, cultural and socioeconomic resources. The formation ecological and economic framework of the territory and the preservation of most valuable landscapes for environmental tourism and maintain a high quality natural environment in the places of recreation.

If the above measures are taken into account, the following types of combined weekly ecotours of international significance could be organized in the Semey region. Ecological and historical tour to the Zhidebay tract (natural boundary), to the Abay mausoleum, $200 \mathrm{~km}$ long.

You can start your trip with a rest in nature, in the suburbs, with a visit to the relict belt forest that surrounds Semey on the north side, along the bank of the Irtysh river.
Tourists can be accommodated in the existing in the area: the building of the dispensary, the hotel of the training camp of the Moscow pedagogical Institute, in the country houses of the city Department and postal workers. In winter visitors can take skiing in a special recreation, in the summer to organize the campaign in an ecological path, which will include the following stations: base camps summer academic teacher's college, old village Fortress, the floodplain of the Irtysh river (the beach), a small church-chapel on the edge of the gorge, which is located on the right side of the track.

After breakfast (lunch), arranged at the training base, you can go on a hike of $1-2 \mathrm{~km}$ in the direction of the village of old fortress, down the bank of the Irtysh river, through a pine forest on a folded path. Along the way, you can talk about the significance of the unique relict pine forest, taken under the protection of the state reserve, tell tourists about the representatives of the local flora and fauna.

In our opinion, in order to preserve the relict pine forest, it is necessary to use the methods of tourist and local history activities (TLHA) of schoolchildren. Tourist and local history activities (hereinafter - TLHA) is a unique model of personal education. In the process of TLHA with the right teaching building integrated in the identity of all major parties education: Patriotic, moral, labour, aesthetic, physical, environmental, intellectual, formed skills research activities are implemented creative abilities, creates favorable conditions for self-knowledge, self-realization and socialization from an early age. The specificity of tourist and local history activities is in the direct "collision" of the child with the surrounding natural and social environment, in which conditions it becomes possible to acquire vital skills, communicative culture, creative and creative experience, thus, TLHA has great educational opportunities.

The wide pedagogical possibilities of TLHA attract both children themselves and their parents, help to unite the team and involve the parent contingent in the pedagogical process.

Children and youth tourism, being an active type of tourism, as well as a unique means of education, contributes to:

- formation of a well-rounded and physically healthy personalities.

- introducing the younger generation to a healthy lifestyle life through communication with nature, as an alternative to drugs and bad habits, education of will and spirituality.

- practical knowledge of the native land, familiarity with historical and cultural monuments, and the surrounding nature.

- organization of active leisure and summer recreation for students. 
- forming the foundations of environmental culture.

- instilling skills of labor, social activity, search and research work, professional orientation.

The theoretical and practical aspects proposed by us are of a research nature and are considered as pedagogical bases necessary for teachers and educators to implement a systematic approach to the education of the child's personality in the conditions of tourist and local history activities. The reliability of the implementation of the proposed model is provided by the author's long-term practice-oriented activity and the representativeness of the results obtained.

Children learn to study and love their native land, their native nature from childhood, and the most fertile ground for this is tourist and local history activities [5].

A tourist-ecological trail is a specially laid and equipped route in places where the surrounding wildlife allows you to get acquainted with natural phenomena and objects and serves to educate environmental and conservation thinking.

The tourist-ecological route is a specially laid and information-provided route, where visitors receive oral (with the help of a guide) and/or written (stands, sold-out, etc.) information about natural and historical-cultural complexes and objects. As a rule, they combine various tourist sites, as well as one or more tourist and ecological trails on the territory of protected areas (specially protected natural areas). The organization of a tourist-ecological trail is one of the forms of education of ecological thinking and outlook [6].

The main purpose of nature trails is to foster a culture of human behavior in nature. Thus, the main goals of creating a tourist - ecological trail can be combined into two groups:

1. tourist-ecological-educational (the combination of active recreation of visitors to tourecopathway in a natural environment with the expansion of their horizons and the formation of environmental culture-as part of the general culture of relations between people and between man and nature).

2. nature protection (localization of visitors to the natural area on a certain route).

The peculiarity of the process of environmental training and education on tourecopathway is that it is built on the basis of non-didactic, but relaxed assimilation of information and norms of behavior in the natural environment. This is achieved by a limited combination of rest and learning while on the route. It is possible to identify the main requirements that apply to the choice of the route of the tourist-ecological trail. Among them:

\section{A. Attractiveness: Aesthetic expressiveness and}

attractiveness of the surrounding landscape in the area where the tourist and ecological trail passes, the trail should not be similar to others and be monotonous;

B. Accessibility: Short length; availability of a good pedestrian or access road to the trail; safety of the chosen route; absence of serious difficulties when moving training groups along the route;

C. Informativeness: The ability to meet the cognitive needs of visitors in the field of natural science disciplines; inclusion of the largest number of natural objects;

D. Recreation: children and campers should feel peaceful, psychologically protected and feel in harmony with nature while on the trails.

In this regard, in our opinion, it is essential to use the help of forestry workers to maximize the involvement and involvement of students who live near the belt forest in environmental activities, for example, planting and growing trees-seedlings, conducting a green patrol or ecoconsultant. Thus, they can control and regulate tourist and environmental protection measures aimed at preserving a unique natural object.

To sum up, the task of all tourist, environmental and nature protection measures is reduced to one - the creation of a biosphere reserve on the territory of the relict pine belt forest.

\section{References}

1. Belgibaev ME, Mazbaev OB, Saparov KT, Asubaev BK, Atasoy E (2014) Origin and preservation of Irtysh relic pine forest of Kazakhstan. Journal of Balkan Ecology 17(2): 153-159.

2. Belgibaev ME (2009) On Origin of Irtysh Relic Pine Forest. In: Geography in Schools and Universities in Kazakhstan, Almaty.

3. Cherepanova A (2011) As heal wounds grandfather's Bora. Spectrum, pp: 8.

4. Shayakhmetova GM (2015) A systematic approach to the education of the individual by means of tourist and local history activities (pre-school, school stages). Bulletin of the Academy of youth tourism and local history. pp: 97122.

5. Oborin MS, Nepomnyashchiy, Vyacheslav V (2010) Development of ecological trails in specially protected natural areas of various natural regions. Perm branch of the St. Petersburg Institute of foreign economic relations, Economics and law. Scientific Bulletin: Natural Sciences Series 21(13): 174-180. 


\section{Journal of Ecology and Natural Resources}

6. Chizhova VP (1996) Nature training trails. Methodical recommendation for nature reserves and national parks
/V. P. Chizhova. - Moscow: Enlightenment, pp: 765.

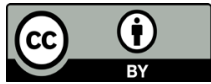

